\title{
TAKING INTO ACCOUNT CONSTRUCTION PARAMETERS OF CRANKSHAFT WHEN EVALUATING CHARACTERISTICS OF ITS EQUIVALENT TORSION SCHEME
}

\author{
Farit Khaliullin $^{1,2}$, Rafis Shaikhutdinov ${ }^{2}$, Renat Shakirov ${ }^{3}$, Alexey Ivanov ${ }^{3}$ \\ ${ }^{1}$ Kazan National Research Technical University named after A. N. Tupolev, Russia; \\ ${ }^{2}$ Kazan State Agrarian University, Russia; ${ }^{3}$ Izhevsk State Agricultural Academy, Russia \\ khaliullin_kai_adis@mail.ru, shaykhutdinov.rafis@mail.ru,renmar@mail.ru, ivalgen@inbox.ru
}

\begin{abstract}
The article is devoted to determine the parameters of the equivalent torsional scheme of the crankshaft of automotive internal combustion engines. The parameters that depend on the design features of the studied engines include the number and moments of inertia of the motor masses, the stiffness of the shaft sections and their length. Currently used methods are based on empirical data and require their identification for each specific model of the engine under study. To improve the adequacy of the data obtained, it is necessary to conduct fullscale tests of the crankshafts for stiffness. Modeling the spatial structure of the crankshaft by finite elements with further determination of the studied parameters, although it facilitates the task, requires subsequent mandatory verification of the model used. To unify the calculation methods and reduce their complexity, it is proposed to consider the elastic-deformable section of the crankshaft, taking into account the geometric parameters. The accuracy of the results obtained depends on the curve equations describing the elastic deformation surface of the crankshaft transition sections. A preliminary evaluation of the crankshaft parameters can be performed on a piecewise linear surface. Reducing the sampling step increases the accuracy of the results. In the same way, we can take into account such design parameters of the crankshaft as the overlap of the necks, the presence of cavities inside the main and connecting rod necks. The proposed method can be used for automate crankshaft calculations of modern automotive internal combustion engines.
\end{abstract}

Keywords: crankpin, crankshaft; equivalent torsion scheme; stiffness; elastic deformation.

\section{Introduction}

The operation of high-forced automotive internal combustion engines is accompanied by the appearance of torsional vibrations of the crankshafts, which leads to a decrease in its effective performance, a deterioration in the emission parameters and a decrease in the resource. The final stage of creating such engines is to calculate the crankshafts for torsional vibrations and take constructive measures to reduce their negative impact $[1 ; 2]$. Therefore, the correct choice of the design scheme of the crankshaft for torsional vibrations and a reasonable calculation method determine the adequacy of the results obtained.

\section{Materials and methods}

In accordance with the standard methodology, the choice of the design scheme depends on the number of motor masses and the accuracy requirements of the calculation results [3]. Bringing the engine dynamic system down to determining the reduced length of individual sections of the crankshaft, i.e. the lengths of the corresponding sections of the rectilinear shaft having the same torsional stiffness as the sections of the real shaft (Fig. 1).

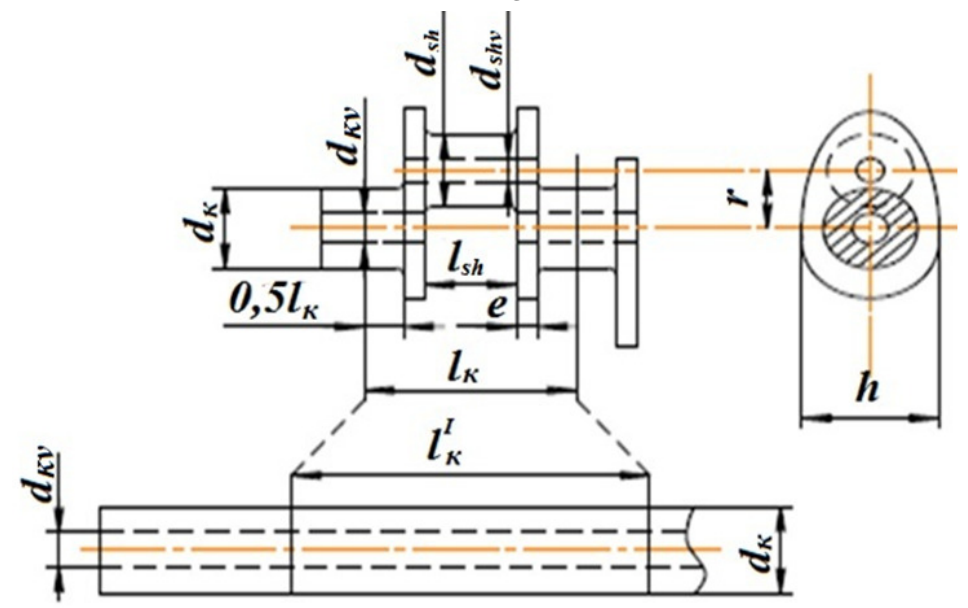

Fig. 1. Crankshaft with hollow necks 
The reduced shaft elbow length is calculated according to semi-empirical formulas obtained by introducing experimental coefficients into formulas based on simplified theoretical considerations.

Let us compare the results of applying the formulas and the effect of the calculated parameters of the crankshaft on the calculated data.

For automobile engines, close to reality results are obtained when calculating the reduced knee length using the Zimanenko formula [4]. Further, the distance between the motor masses determined by this formula will be denoted as $l_{k o l}^{\prime}(9)$.

For a crankshaft with hollow necks, the formula looks like

$$
l_{k o l}^{\prime}=\left(l_{k}+0.6 \frac{e}{l_{k}} \cdot d_{k}\right)+\left(0.8 \cdot l_{s h}+0.2 \cdot \frac{e}{r} \cdot d_{k}\right) \cdot \frac{d_{k}{ }^{4}-d_{k v}{ }^{4}}{d_{s h}{ }^{4}-d_{s h v}}+\frac{r \sqrt{r}}{\sqrt{d_{s h}}} \cdot \frac{d_{k}{ }^{4}-d_{k v}{ }^{4}}{e \cdot h^{3}},
$$

where $d_{k}$ - diameter of the crankshaft main journal, m;

$d_{k v}$ - diameter of the inner shaft cavity of the crankshaft main journal, m;

$d_{s h}-$ crankpin journal diameter, $\mathrm{m}$;

$d_{s h v}$ - diameter of the inner shaft cavity of the crankshaft crankpin journal, m;

$l_{s h}-$ crankpin journal length, $\mathrm{m}$;

$l_{k}-$ length of the crankshaft main journal, $\mathrm{m}$;

$e$ - thickness of the cheek, m;

$h$ - width of the cheek, m;

$r$ - radius of the crank, $m$.

For a crankshaft with solid necks $\left(d_{k v}=0, d_{s h v}=0\right)$

$$
l_{k o l}^{\prime}(9)=\left(l_{k}+0.6 \frac{e}{l_{k}} \cdot d_{k}\right)+\left(0.8 \cdot l_{s h}+0.2 \cdot \frac{e}{r} \cdot d_{k}\right) \cdot \frac{d_{k}{ }^{4}}{d_{s h}{ }^{4}}+\frac{r \sqrt{r}}{\sqrt{d_{s h}}} \cdot \frac{d_{k}{ }^{4}}{e \cdot h^{3}} .
$$

The formula of the Kolomna plant - for the shafts of engines of medium and higher power. The distance between engine masses determined by this formula will be denoted as $l_{k o l}^{\prime}(10)$.

$$
\begin{gathered}
l_{k o l}^{\prime}(10)=\frac{l_{k}}{d_{k}{ }^{4}-d_{k v}{ }^{4}}+\frac{l_{s h}}{d_{s h}{ }^{4}-d_{s h v}{ }^{4}}+ \\
+1.8 \cdot \frac{r}{2 \cdot e \cdot h^{3}}\left(1+\frac{0.64}{r^{2}} \cdot \sqrt[3]{\left.\frac{\left(d_{k}{ }^{4}-d_{k v}{ }^{4}\right)\left(d_{s h}{ }^{4}-d_{s h v}{ }^{4}\right)}{r^{2}}\right)} .\right.
\end{gathered}
$$

Carter formula - for shafts of light high-speed engines [4]. The distance between engine masses determined by this formula will be denoted as $l_{k o l}^{\prime}(11)$

$$
l_{k o l}^{\prime}(11)=\frac{l_{k}+0.8 \cdot e}{d_{k}{ }^{4}-d_{k v}{ }^{4}}+\frac{0.75 \cdot l_{s h}}{d_{s h}{ }^{4}-d_{s h v}{ }^{4}}+1.5 \frac{r}{e \cdot h^{3}} .
$$

Taplin formula - for shafts of a wide variety of engines [4]. The distance between engine masses determined by this formula will be denoted as $l_{k o l}^{\prime}(12)$

$$
\begin{aligned}
& l_{k o l}^{\prime}(12)=\frac{\left(l_{k}+0.15 \cdot d_{k}\right)}{\left(d_{k}{ }^{4}-d_{k v}{ }^{4}\right)^{2}} \cdot d_{k}{ }^{4}-\frac{l_{s h}+0.15 \cdot d_{s h v}}{\left(d_{s h}{ }^{4}-d_{s h v}{ }^{4}\right)^{2}} \cdot d_{s h v}{ }^{4}+ \\
& \frac{+2 e-0.15\left(d_{s h}-d_{k}\right)}{h^{4}-d_{s h v}{ }^{4}}+\frac{0.065 \cdot d_{k}+0.58 \cdot e}{e^{2} \cdot h^{3}} r+\frac{0.16}{h \cdot e^{2}} .
\end{aligned}
$$

\section{Results and discussion}

The obtained results depend on the spatial structure of the crankshaft scheme and its design parameters and may differ by 5-7\% from the experimental data [5]. Therefore, to unify the calculation methods and reduce their complexity, it is proposed to consider the elastic-deformable section of the crankshaft, taking into account its geometric parameters [6;7]. 
The formula for determining the reduced length of a compound knee, where the axes of the main and crankpin journals lie in the same plane, will be denoted as $l_{k o l}^{\prime}(16)$

$$
\begin{gathered}
l_{k o l}^{\prime}(16)=\left(l_{k}+0.6 \frac{e_{1}}{l_{k}} d_{k}\right)+\left(0.8 \cdot l_{s h}+0.2 \frac{h_{1}}{r} d_{k}\right) \cdot \frac{d_{k}{ }^{4}-d_{k v}{ }^{4}}{d_{s h}{ }^{4}-d_{s h v}{ }^{4}}+ \\
+\left(0.8 \cdot l_{s h}+0.2 \frac{h_{2}}{r} d_{k}\right) \frac{d_{k}{ }^{4}-d_{k v}{ }^{4}}{d_{s h}{ }^{4}-d_{s h v}{ }^{4}}+\frac{r \sqrt{r}}{\sqrt{d_{s h}}}\left(\frac{d_{k}{ }^{4}-d_{k v}{ }^{4}}{e_{1} \cdot h_{1}{ }^{3}}+\frac{d_{k}{ }^{4}-d_{k v}{ }^{4}}{e_{2} \cdot h_{2}{ }^{3}}\right) .
\end{gathered}
$$

Let us consider the influence of the design parameters of the crankshaft on the results of its calculations for torsional vibrations, when determining the parameters of an equivalent torsional scheme on the example of a spark six-cylinder four-stroke opposite engine with a nominal power of $\mathrm{Ne}=170 \mathrm{~kW}[8 ; 9]$.

The following geometric parameters of the crankshaft of this engine are used as input data:

diameter of the crankshaft main journal $d_{k}=0.045 \mathrm{~m}$; crankpin journal diameter $d_{s h}=0.045 \mathrm{~m}$; length of the crankshaft main journal $l_{k}=0.026 \mathrm{~m}$; crankpin journal length $l_{s h}=0.026 \mathrm{~m}$; thickness of the cheek $e=0.008 \mathrm{~m}$; width of the cheek $h=0.1 \mathrm{~m}$; radius of the crank $r=0.0366 \mathrm{~m}$; diameter of the inner shaft cavity $d_{k v}=0, d_{s h v}=0$.

For comparison of various formulas the reduced length is considered as a function of the dependence on the diameter of the main journal $l_{k o l}^{\prime}=f\left(d_{k}\right)$ on the diameter of the crankpin journal $l_{k o l}^{\prime}=f\left(d_{s h}\right)$, on the length of the main journal $l_{k o l}^{\prime}=f\left(l_{k}\right)$ and the length of the crankpin journal $l_{k o l}^{\prime}=f\left(l_{s h}\right)$. Other parameters are accepted as permanent.

To do this, the range of values in the segment is defined $d_{s h}=[0.045-0.055], d_{k}=[0.045-0.055]$, $l_{k}=[0.026-0.036], l_{s h}=[0.026-0.036]$, in increments $0.001 \mathrm{~m}$.

Fig. 2 shows the effect of changing the diameter of the crankshaft root neck on the reduced length of the equivalent design scheme. According to the figure, the most invariant are the results of calculations using formulas (2), (4) and (6).

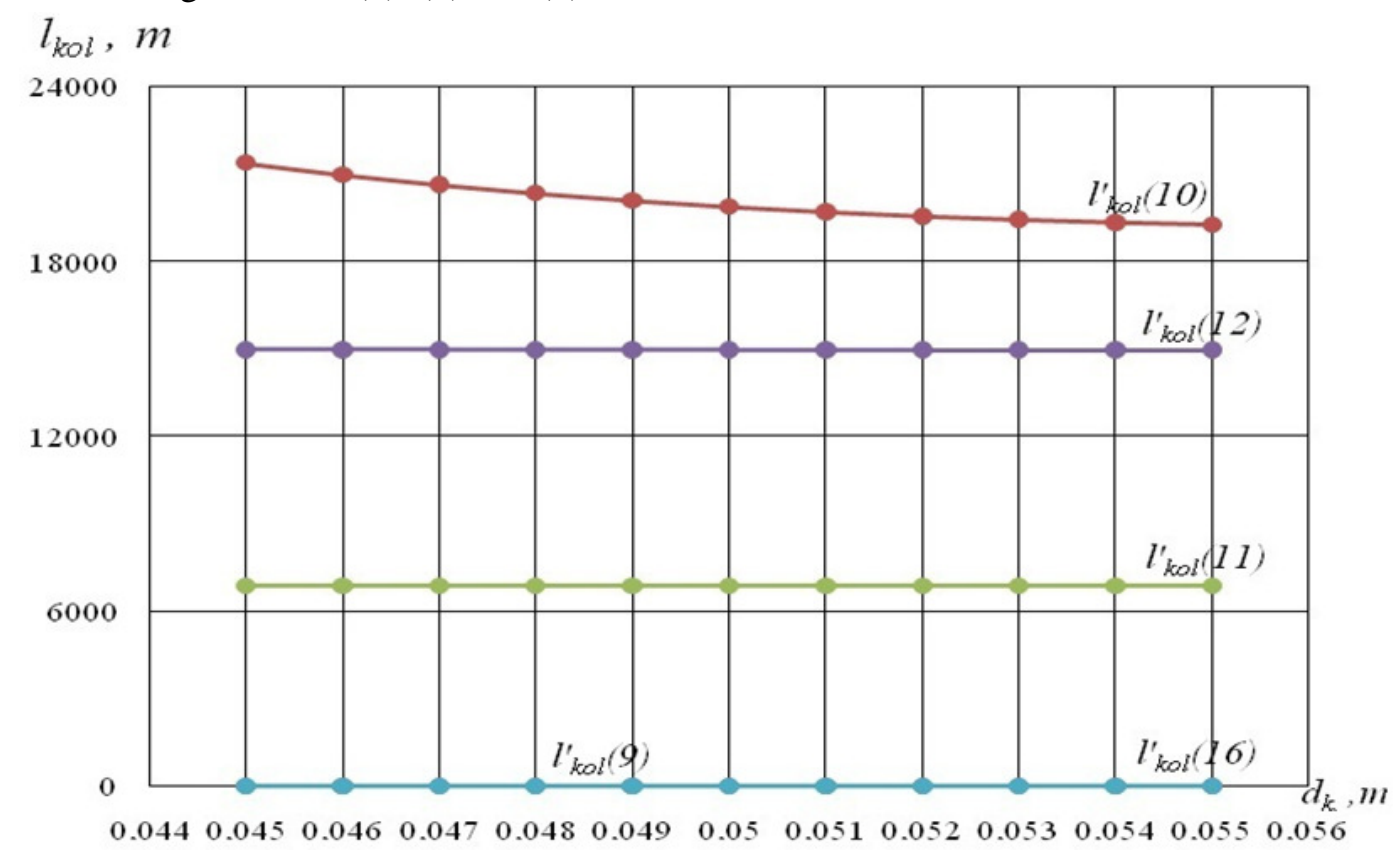

Fig. 2. Influence of the diameter of the main journal on the reduced length

In the future, we will consider the influence of individual parameters for each of the formulas.

Fig. 3 shows a graph comparing the impact of the crankshaft parameters $d_{k}, d_{s h}, l_{k}$ and $l_{s h}$ on the value of the reduced length for the Zimanenko formula.

It can be seen from the graph that as the length of the main and crankpin journals increases, the reduced length will increase, and, accordingly, the rigidity of the shaft section will decrease. 


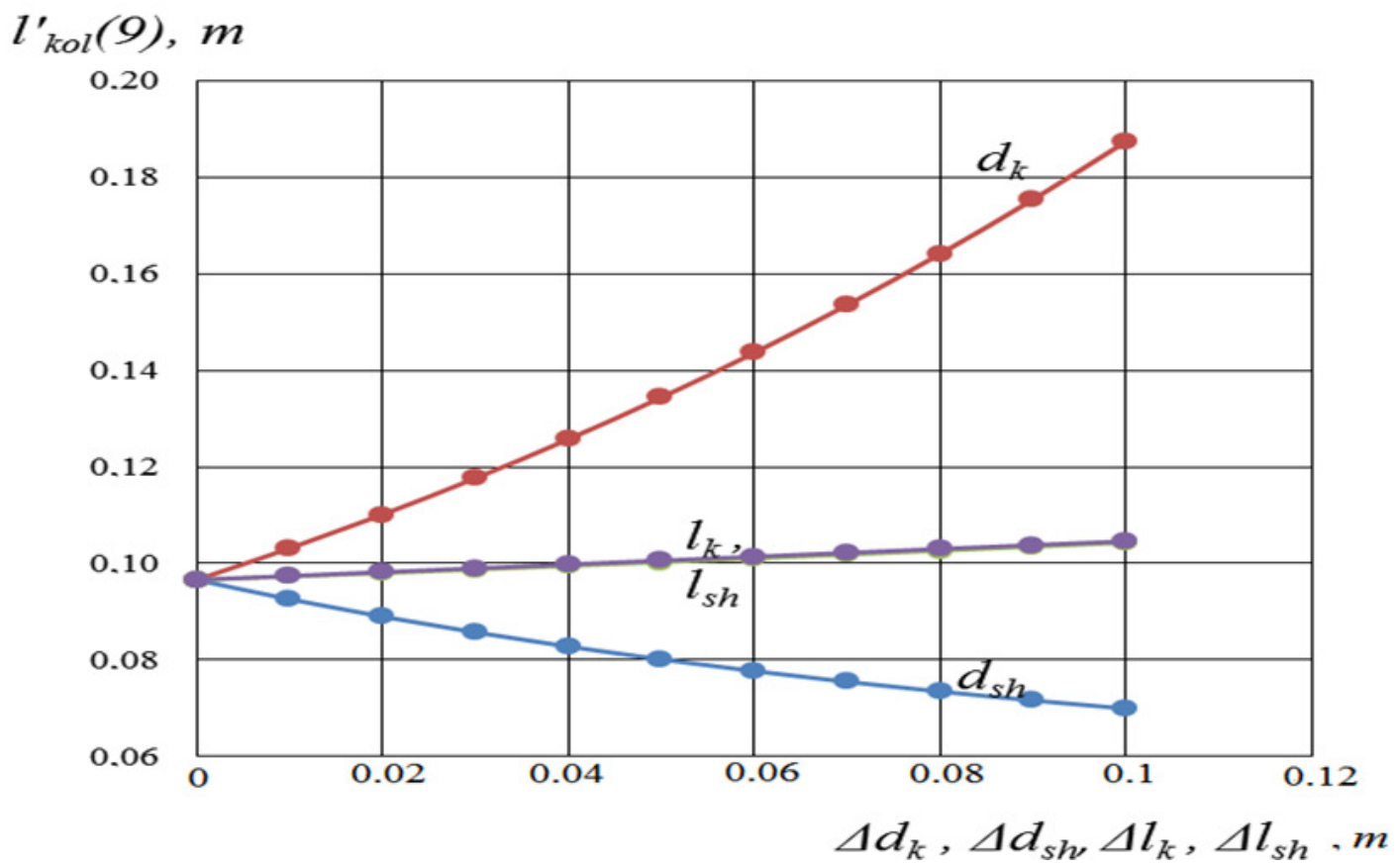

Fig. 3. Influence of design parameters on the reduced length by Zimanenko formula

An increase in the diameter of the crankpin journal leads to a decrease in the reduced length of the shaft section, and, therefore, to an increase in the rigidity of the shaft section. The inverse result gave an increase in the diameter of the main journal - if it increases, the reduced length increases and the stiffness decreases.

Fig. 4 shows a graph comparing the influence of the crankshaft parameters $d_{k}, d_{s h}, l_{k}$ and $l_{s h}$ on the value of the reduced length for the formula of the Kolomna plant.

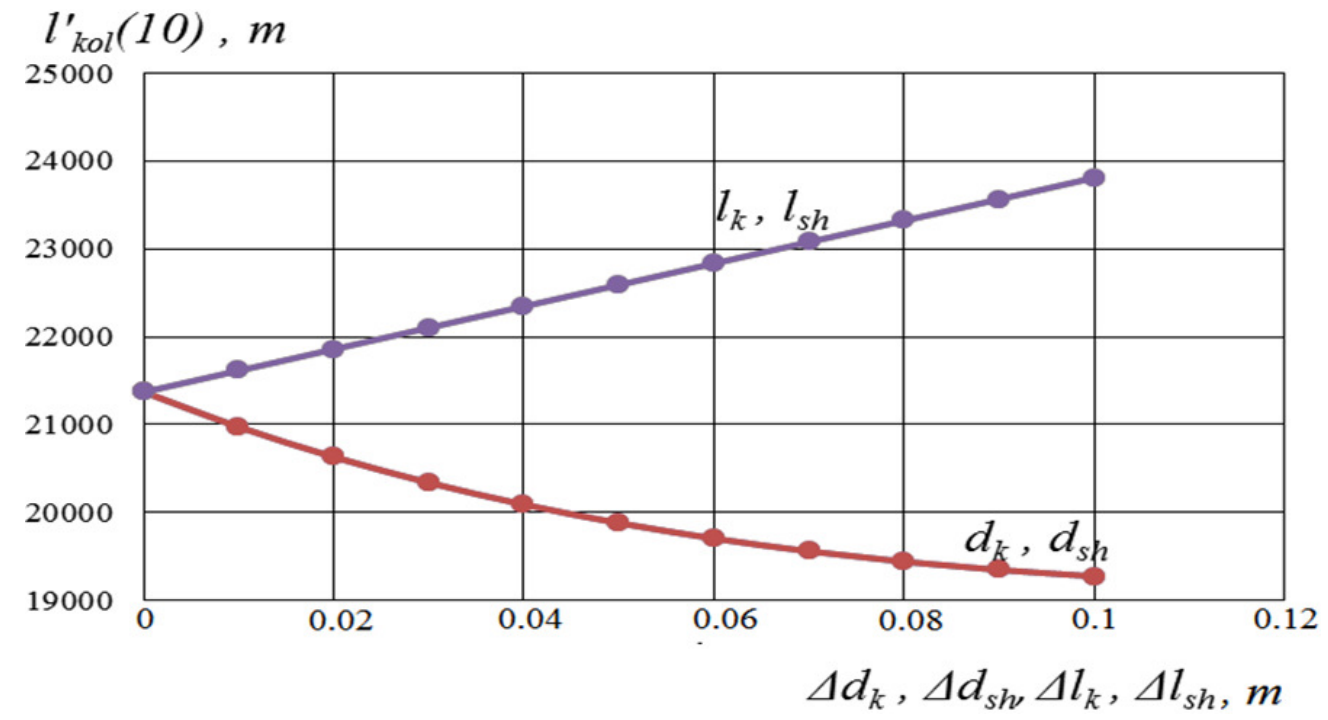

Fig. 4. Influence of design parameters on the reduced length according to the formula of the Kolomna plant

The graph shows that when the length of the main and crankpin journals increases, the reduced length will increase, respectively, the rigidity of the shaft section will decrease. An increase in the diameter of the main and crankpin journal leads to a decrease in the reduced length of the shaft section, and therefore to an increase in the rigidity of the shaft section.

The influence of design parameters on the reduced length according to the Carter formula is shown in Fig. 5. 


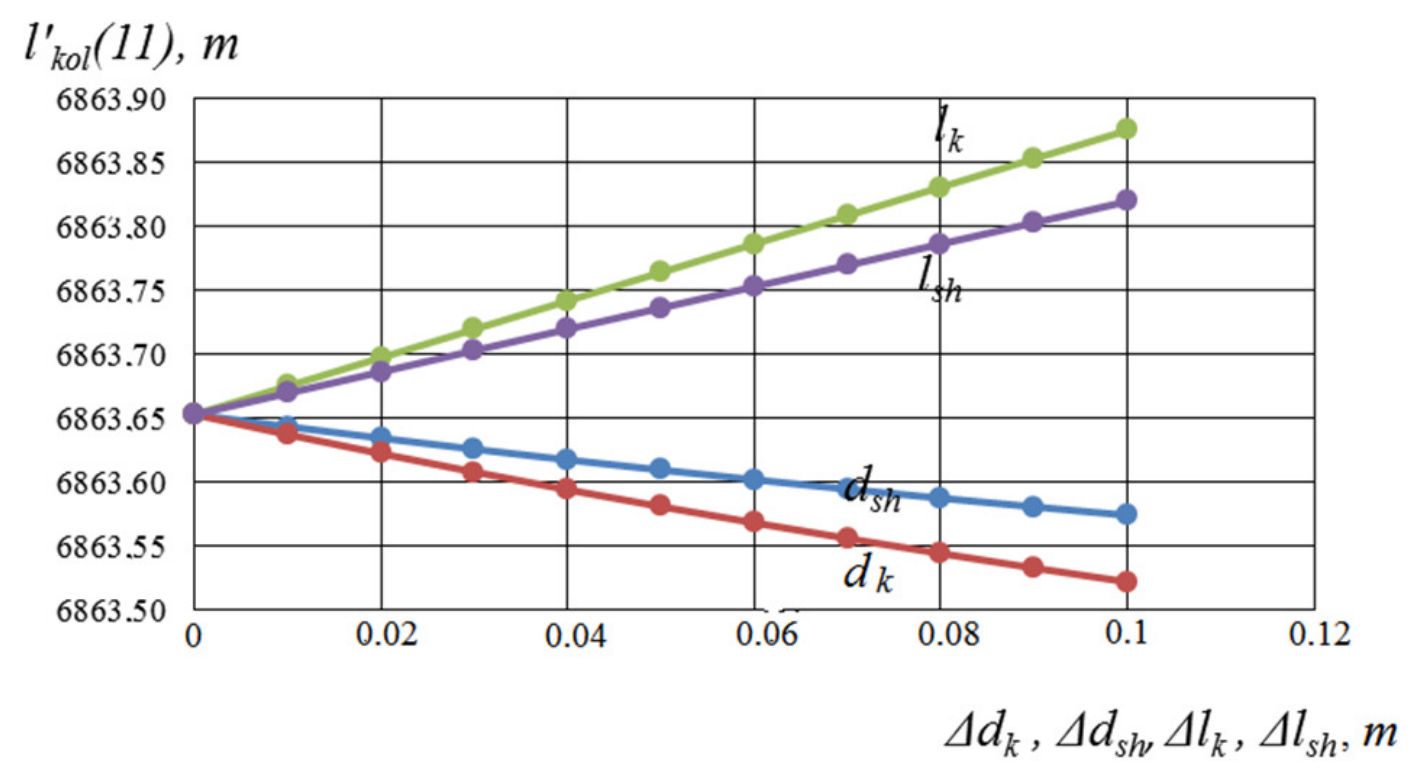

Fig. 5. Influence of design parameters on the reduced length according to the Carter formula

The graph shows that with increasing the length of the main and crankpin journals, the reduced length will increase, respectively, the stiffness of the shaft section will decrease, while increasing the length of the main journal has a stronger effect on reducing the stiffness of the shaft section The increase in the diameter of the main and crankpin journals reduces the length of the given section of the shaft, and hence to increase the stiffness of the area of the shaft, increasing the diameter of the main journal leads to a greater increase of the stiffness of the section of the shaft.

Fig. 6 shows a graph comparing the impact of the crankshaft parameters $d_{k}, d_{s h}, l_{k}$ and $l_{s h}$ on the value of the reduced length for the Taplin formula.

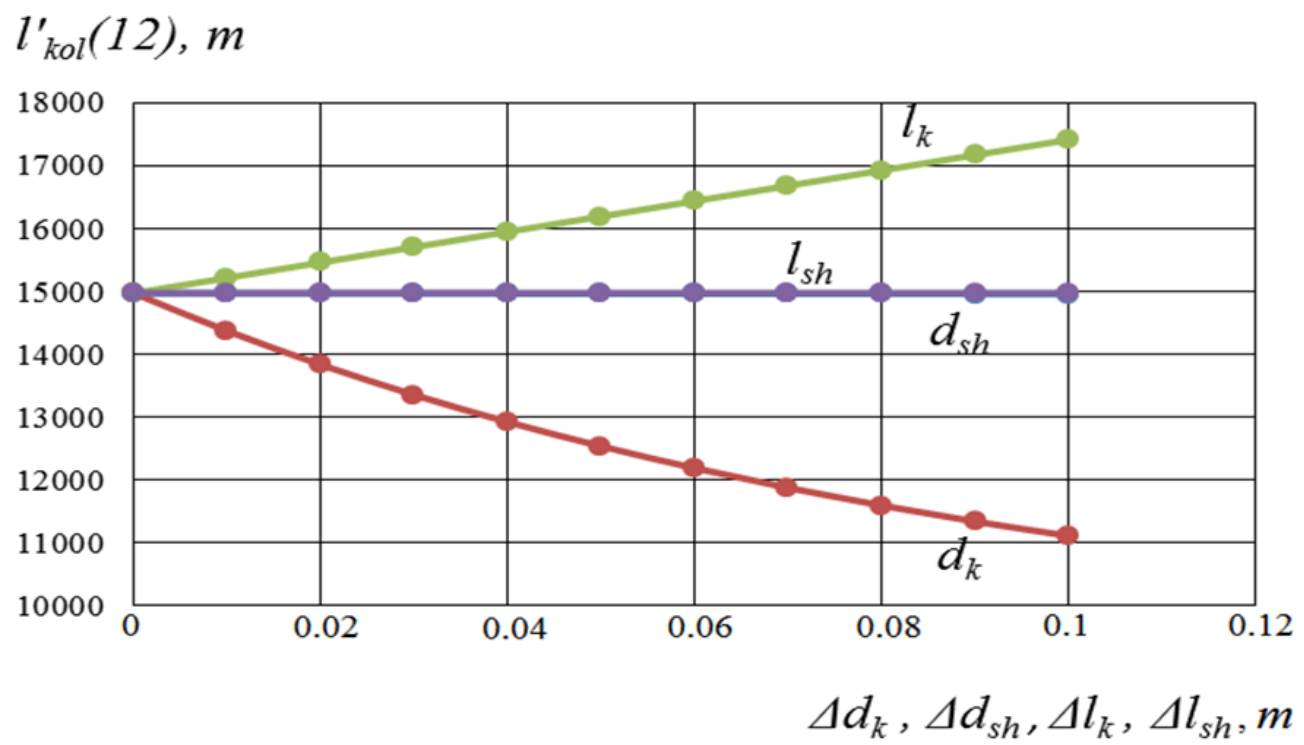

Fig. 6. Influence of design parameters on the reduced length according to Taplin formula

The graph shows that as the length of the main journal increases, the reduced length will increase, respectively, the stiffness of the shaft section will decrease. An increase in the diameter of the crankshaft main journal leads to a decrease in the reduced length of the shaft section, and, therefore, to an increase in the rigidity of the shaft section. At the parameters of $d_{k v}=0, d_{s h v}=0$, increase of the crankpin journal length and crankpin journal diameter does not result in special change of reduced length.

The influence of design parameters on the reduced length according to the formula for determining the reduced length of a complex knee is shown in Fig. 7. 


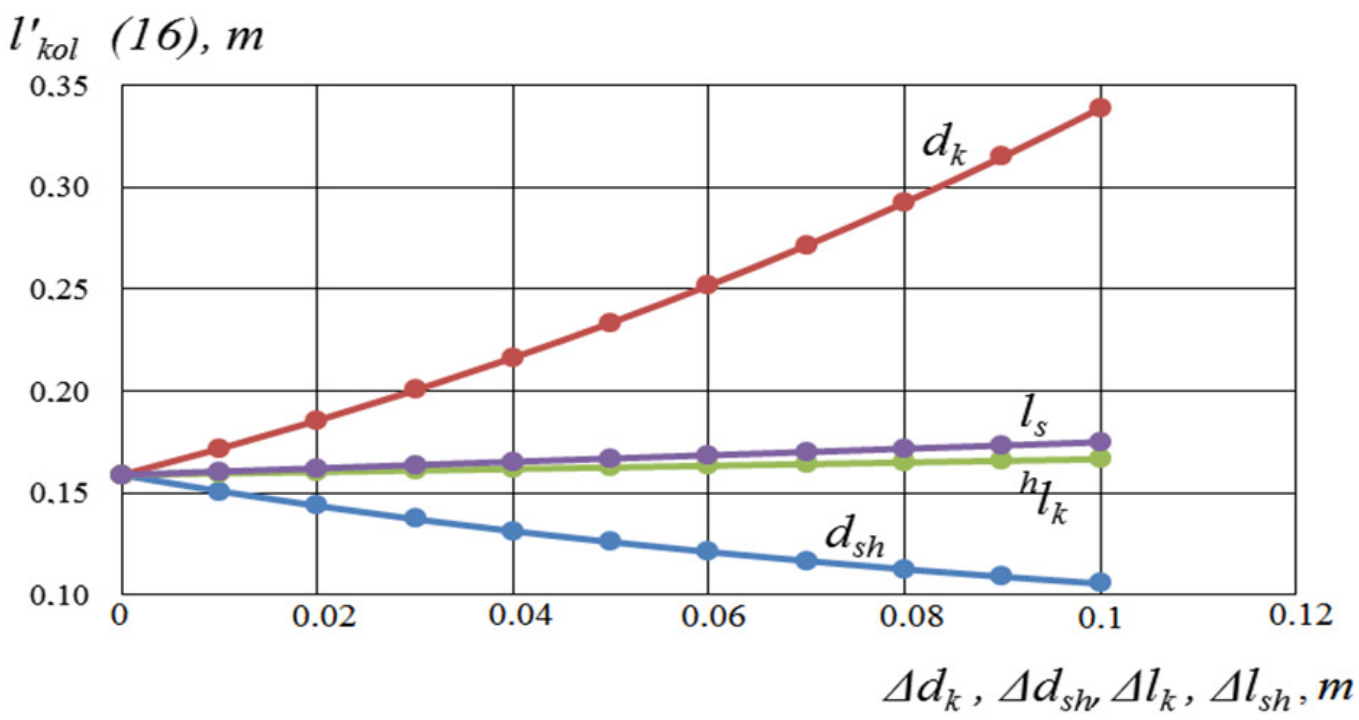

Fig. 7. Influence of design parameters on the reduced length according to the formula for determining the reduced length of a complex knee

The graph shows that when the length of the main and crankpin journals increases, the reduced length will increase, respectively, the stiffness of the shaft section will decrease, and increasing the length of the crankpin journal gives a greater increase in the reduced length. An increase in the diameter of the crankpin journal leads to a decrease in the reduced length of the shaft section, and therefore to an increase in the rigidity of the shaft section. The opposite result was an increase in the diameter of the main journal, with its increase, the reduced length increases, and the stiffness decreases.

\section{Conclusions}

The resulting calculations and graphs show that these formulas were derived for different engines and crankshafts.From most calculations and graphs, it is concluded that an increase in the diameters of the necks and an increase in the overlap of the necks increases the stiffness of the shaft, an increase in the lengths of the necks, on the contrary, reduces the stiffness of the shaft. The values given length closest to reality of the values shown in Zimanenko formula and formula for identification of given length of the complex knee, is the axis of the root and connecting rod journals in one plane. According to the change in the given length, depending on the diameters and lengths of the crankshaft main and crankpin journals, good results were shown by the formulas of the Kolomna plant and the Carter formula.

\section{References}

[1] Troy Feese P.E., Hill C. Guidelines for preventing torsional vibration problems in reciprocating machinery.San Antonio, Texas, 2002, 45 p.

[2] Khafizov C.A., Usenkov R.A., Khalyullin F.K., Latypov R.A. The thermodynamic calculation of offset shafts rotary engine ideal cycle with external heat supply // International Journal of Mechanical and Production Engineering Research and Development(IJMPERD) ISSN(P): 22496890; ISSN(E): 2249-8001 Vol. 9, Issue 4, Aug 2019, pp. 1109-1116.

[3] Wang Y., Lim T. C. Prediction of torsional damping coefficients in reciprocating engine/Journal of sound and vibration. The university of Alabama, 2000, pp. 710-719.

[4] Дизели. Справочное пособие конструктора. Под ред. В.А.Ваншейдта (Dizeli. Spravochnoye posobiye konstruktora. Pod red. V.A.Vansheydta / M .: Mashgiz, 1957. 442 p. (In Russian).

[5] Галиев И.Г., Хафизов К.А., Адигамов Н.Р., Хусаинов Р.К. Повышение эффективности использования тракторов в сельскохозяйственном производстве (Increase of efficiency of tractors use in agricultural production) //17th International Scientific Conference Engineering for rural development Proceedings. Volume 17, May 23-25, 2018, pp. 373-377. (In Russian). 
[6] Chao C.P., Show S.W., Lee C.T. Stability of the unison response for a rotating system with multiple tautochronic pendulum vibration absorbers. Transactions of ASME: Journal of appl. Mechanicas. 1997, №1. pp. 149-156.

[7] Халиуллин F.Kh., Матросов B. М. Конструктивные параметры и характеристики крутильных колебаний коленчатого вала ДВС (Konstruktivnyye parametry i kharakteristiki krutilnykh kolebaniy kolenchatogo vala DVS // Avtomobilnaya promyshlennost. 2010. №11. pp. 7-8. (In Russian).

[8] Khaliullin F.Kh., Matyashin A.V, Akhmetzyanov R.R., Medvedev V.M., Lushnov M.A. Prospects for using the Bayes algorithm for assessing the technical condition of internal combustion engines // IOP Conference Series: Materials Science and Engineering, Volume 635, 10th International Conference on Mechatronics and Manufacturing (ICMM 2019) 21-23 January 2019, Bangkok, Thailand, DOI: 10.1088/1757-899X/635/1/012016.

[9] STE Schwingungstechnik. Maintenance Instruction for Viscous Torsional Vibration Dampers (VTD), 1996, 6 p. 